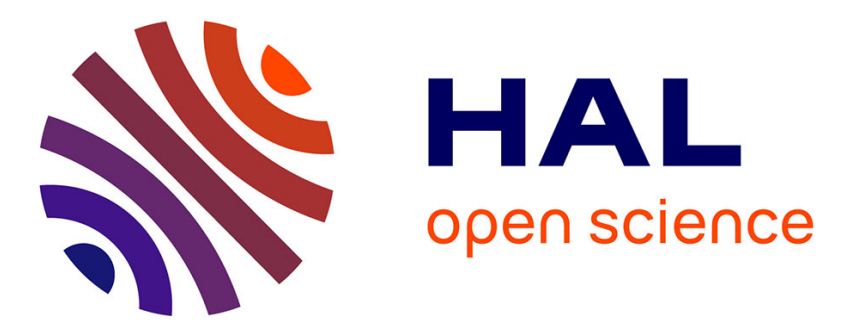

\title{
How to Optimize Axial Correction Without Altering Thoracic Sagittal Alignment in Hybrid Constructs With Sublaminar Bands: Description of the "Frame" Technique
}

Brice Ilharreborde, Anne Laure Simon, Emmanuelle Ferrero, Keyvan Mazda

\section{To cite this version:}

Brice Ilharreborde, Anne Laure Simon, Emmanuelle Ferrero, Keyvan Mazda. How to Optimize Axial Correction Without Altering Thoracic Sagittal Alignment in Hybrid Constructs With Sublaminar Bands: Description of the "Frame" Technique. Spine Deformity, 2019, 7, pp.245 - 253. 10.1016/j.jspd.2018.08.013 . hal-03486304

\author{
HAL Id: hal-03486304 \\ https://hal.science/hal-03486304
}

Submitted on 20 Dec 2021

HAL is a multi-disciplinary open access archive for the deposit and dissemination of scientific research documents, whether they are published or not. The documents may come from teaching and research institutions in France or abroad, or from public or private research centers.
L'archive ouverte pluridisciplinaire HAL, est destinée au dépôt et à la diffusion de documents scientifiques de niveau recherche, publiés ou non, émanant des établissements d'enseignement et de recherche français ou étrangers, des laboratoires publics ou privés.

\section{(ㄷ)(1) $\$$}

Distributed under a Creative Commons Attribution - NonCommerciall 4.0 International 


\section{How to optimize axial correction without altering thoracic sagittal alignment in hybrid constructs with sublaminar bands: description of the « frame » technique \\ B. Ilharreborde, AL. Simon, E. Ferrero, K. Mazda}

\section{Corresponding author:}

Pr Brice Ilharreborde

Department of pediatric orthopaedics, Robert Debré Hospital,

AP-HP, Paris Diderot University

48 Bd Sérurier, 75019 Paris, FRANCE

Phone: +33140033687

Fax: +33140035791

E-mail: brice.ilharreborde @aphp.fr

${ }^{1}$ Department of pediatric orthopaedics

Robert Debré Hospital, AP-HP, Paris Diderot University

48 Bd Sérurier, 75019 Paris, FRANCE

None of the authors received financial support for this study

BI reports to be a consultant for Implanet, ZimmerBiomet and Medtronic

$\mathrm{KM}$ reports to be consultant for Implanet

Retrospective study approved by the Local Ethic Committee 


\section{INTRODUCTION}

Thoracic adolescent idiopathic scoliosis (AIS) is a progressive three-dimensional deformity, responsible for rib cage axial asymmetry and sagittal curves flattening. The goal of surgery is to achieve 3D correction and to prevent progression of the unfused spine, while improving the overall cosmetic aspect of the trunk [1]. Since recent studies have showed that self-image was the only domain that differed at long-term between untreated AIS and healthy controls, reducing the clinical rib hump should remain the treatment's major objective [2-5]. Thoracic pedicle screws associated with direct vertebral (DVD) or "en bloc" derotation techniques have gained popularity after the mid 1990's [5,6]. However, this gain in axial correction has been obtained at the expense of postoperative sagittal alignment, frequently altered in all-screw constructs [7-10]. As a matter of fact, all techniques emphasizing apical axial correction tend to place the anterior and convex higher vertebral wall in a more ventral position, thus increasing the length of the anterior column and therefore flattening the spine [11]. While some authors advocate the use of larger diameter rods, higher screw density on the concave side or multiple facetectomies to optimize the correction of the thoracic hypokyphosis, Mazda et al. and Ilharreborde et al. have emphasized since 2009 the efficacy and safety of a new posteromedial translation technique, even in large stiff curves, with no need for previous thoracoscopic anterior release [12-20]. The latter technique has been largely inspired by previous translation reduction methods, described by Luque, Dove or Asher et al., but sublaminar wires have been replaced by more efficient polyester bands with a dedicated tensioning tool [21-24]. The conclusions of the promoters of the technique have later been confirmed by several independent studies [25-28]. However, Pizones et al. recently questioned the ability of the sublaminar band to correct the axial plane, after noticing

intraoperatively that the tightening of concave sublaminar wires during the correction maneuver tended to create an opposite effect than that desired, making the vertebra rotate 
clockwise instead of counterclockwise, and thus increasing RVA and the rib hump [29]. This observation of great importance had been encountered by the authors in their preliminary experience with severe curves, but has been addressed by a technical improvement emphasizing axial correction. The goal of this paper is therefore to describe the "frame" reduction technique and report the $3 \mathrm{D}$ quantitative analysis of postoperative corrections in a recent consecutive series of thoracic AIS patients.

\section{MATERIALS AND METHODS}

\section{Patients}

Following institutional review board approval, a consecutive series of AIS patients, operated for progressive Lenke 1 or 2 curves between September 2014 and September 2015, were retrospectively analyzed. The apex and both end vertebrae (upper and lower) of the main thoracic curve were determined by an independent senior spine surgeon. Demographic and surgical data was collected. A minimum 2-year follow-up was required. All patients were evaluated preoperatively, in the early postoperative period (within $1 \mathrm{month}$ ), and at latest follow-up. None of the patients had prior spinal surgery.

\section{Surgical procedure}

All patients underwent posterior spinal fusion using hybrid constructs, combining pedicle screws (below the inflection point, from T11 to L4) (ISS (Implanet, Bordeaux, France) or Legacy (Medtronic, Minneapolis, USA)), concave thoracic sublaminar bands (above the inflection point, from T5 to T11) (Jazz systems (Implanet, Bordeaux, France) and proximal hooks with $5.5 \mathrm{~mm} \mathrm{CoCr}$ diameter rods, as previously reported [30,31]. No selective thoracic fusion was performed and no patient underwent prior anterior release before posterior fusion. 
Facetectomies were systematically performed at every level but no additional posterior osteotomy was used. The same perioperative blood saving strategy was used, associating intraoperative cell saver and tranexamic acid. Posteromedial translation was the main technique used for thoracic correction, using the progressive tension transmitted by the polyester bands to bring the thoracic spine to precontoured rods. Autograft was the only material used for fusion and spinal cord monitoring was systematically applied.

\section{Implants location and reduction maneuver using the "frame » technique}

After pedicle screw insertion below the inflection point (minimum 4 screws, 2 per side), sublaminar bands were placed at every level of the main thoracic curve (upper end vertebra to lower end vertebra) on the concave side. One additional convex sublaminar band was placed at the apex for construct stabilization. The upper fixation relied on a bivertebral claw in all cases, using angled supralaminar hooks on the UIV and either bands (Jazz claw, Implanet, Bordeaux, France) or pedicle hooks (Instinct autostable claw, ZimmerBiomet, Warsaw, USA) on the UIV-1, depending on surgeon's preference (Figures 1,2). Two additional sublaminar bands were often placed on the UIV-3 in order to reduce the pull-out forces on the proximal anchor (Figure 1).

Once all implants were placed (no fluoroscopy or any imaging guidance required), $25.5 \mathrm{~mm}$ $\mathrm{CoCr}$ rods were bent in the sagittal plane according to preoperative planning. Attention was paid to respect the preoperative inflection point, give a lumbar lordosis adapted to pelvic incidence, and restore as much as possible the thoracic kyphosis without modifying the 3D preoperative location of the UIV. The 2 rods were bent in the same manner and no overbending was used on the concave side.

At that stage, both rods were connected before insertion by 1 or 2 fixed transverse connectors $(25,30$ or $35 \mathrm{~mm}$ length depending on patient's anatomy), in order to obtain a frame (Figure 
3). One connector was systematically placed at the apex in order to rigidify the construct and avoid rod flattening during the correction. The first step of the correction was the frame insertion in the pedicle screws. Lumbar correction was first performed using derotation and convex compression. The second step was the connection of the frame with the upper anchors on both sides, with the set screws left open in order to allow spinal lengthening (Figure 4). Sublaminar bands were then connected to their respective rods (3 to 7 bands on the concave side, and 1 or 2 on the convex rod). The thoracic deformity was then progressively reduced by the tension transmitted by the concave polyester bands to bring the vertebrae to the precontoured frame. The spine was first translated medially and posteriorly, but when the convex rod came in contact with the rotated right lamina of the apex, the location of the vertebral center of rotation was modified. The latter shifted posteriorly and therefore emphasized the counterclockwise axial correction during the last stage of correction (Figure 5). After applying the maximal tension on each band, contraction and/or distraction were applied on the proximal claws to achieve shoulders and T1 frontal balance and all set screws were locked.

\section{Radiological measurements}

All patients underwent low-dose stereoradiographs using the EOS system (EOS imaging, Paris, France) preoperatively and at latest follow-up, as previously described [32,33]. 3D reconstructions were performed using SterEOS software (EOS imaging, Paris, France) by an independent Imaging reconstruction service (EOS 3DServices, Montreal, Canada). Inter and intraobserver reliabilities of both methods have been previously reported [34,35]. All 3D measurements were calculated using to the patient's plane, using the central hip vertical axis (CHVA) as a reference, and were therefore not influenced by the patient's position in the EOS device. 
The following 3D coronal radiographic parameters were recorded: Cobb angles of the main curve and T1 tilt (measured between the horizontal reference line and the upper endplate of T1). Sagittal 3D parameters included: T1T12 and T4T12 thoracic kyphosis (TK), L1S1 lumbar lordosis (LL), and pelvic parameters. Sagittal and frontal global balances were evaluated by the projections in the respective planes of the distance between the centre of $\mathrm{T} 1$ vertebral body and the CHVA. In addition, the axial rotations of the apical vertebra (AVR), the upper instrumented vertebra (UIV), the UIV+1, the lower instrumented vertebra (LIV) and the LIV+1 were calculated. Considering the measurement bias in the axial plane, a residual axial rotation $>10^{\circ}$ was considered significant, especially if it affected 2 consecutive vertebrae (LIV and LIV+1 or UIV and UIV+1).

\section{Statistical analysis}

Statistical analysis was performed using SPSS version 12.0 (SPSS Inc, Chicago, IL, USA).

Continuous variables were expressed as means and standard deviations. Paired-samples Student's $t$-tests were used to compare preoperative and postoperative radiological parameters. Pearson test was used to analyze the correlation between the gain in thoracic kyphosis and the axial correction of the apical vertebra (AVR). All statistical tests were 2tailed, and a $p$-value $<0.05$ was considered to be significant.

\section{RESULTS}

Demographic and operative data

Among the 64 eligible Lenke 1 and 2 AIS patients operated during the study period, 4 were excluded because the personalized 3D reconstructions were not feasible. The reason was the existence of lumbosacral transitional anomaly (lumbarized S1 or sacralized L5) altering 
vertebrae numbering on SterEOS software. Mean age of the 60 patients kept for analysis was 15.4 years $( \pm 2)$. There were 6 boys and 54 girls, with a mean follow-up of 28.2 months $( \pm 4)$. Lenke 1 curves were the most frequent (44 cases, 73.3\%), while Lenke 2 curves were identified in 16 patients $(26.6 \%)$. The mean operative time was $208 \pm 25$ minutes, and intraoperative blood loss averaged $300 \pm 65 \mathrm{~mL}$, similar to what had been experienced with the classical bands technique [36]. The number of fused vertebrae averaged $12.9( \pm 1)$, and all fusions extended to L2 or below (no selective thoracic fusion). The UIV was T2 in 20 cases (33.3\%) and $\mathrm{T} 3$ in 40 patients $(66.6 \%)$. The mean number of sublaminar bands used for correction at thoracic levels was $6( \pm 1.5)$.

\section{Frontal correction}

Preoperative and postoperative 3D measurements are reported in Table 1. Frontal correction rate averaged $64 \%( \pm 11$, from $40 \%$ to $84 \%)$, and $75 \%$ of the patients had a residual Cobb angle $<25^{\circ}$ postoperatively. The surgical correction tended to raise the left shoulder in $95 \%$ of the patients (57/60), but a residual $\mathrm{T} 1$ tilt $>10^{\circ}$ (to the right) in the early postoperative period was only noted in 10 cases $(16.6 \%)$. The distance from the center of the apical vertebra to the reference axis (CHVA) in the frontal plane was reduced from $4.7 \mathrm{~cm}( \pm 2)$ to $1.1 \mathrm{~cm}( \pm 1)$, showing the efficient medial translation of the spine during correction $(\mathrm{p}<0.001)$.

\section{Sagittal correction}

The T1T12 kyphosis significantly increased after surgery $(\mathrm{p}<0.001)$, but the instrumented T4T12 kyphosis remained stable ( $\mathrm{p}=0.719)$. However, the high proportion of normokyphotic patients preoperatively (76.6\% with $\mathrm{T} 4 \mathrm{~T} 12$ sagittal Cobb between $10^{\circ}$ and $40^{\circ}$ ) require further analysis. Among the 46 normokyphotic patients preoperatively, 12 (26\%) had an unintentional reduction of T4T12 kyphosis $>5^{\circ}$, while $74 \%$ remained with a stable sagittal 
alignment or gained kyphosis. Mean increase in the 12 most challenging hypokyphotic patients (i.e T4T12 sagittal Cobb $<10^{\circ}$ ) was $8.5^{\circ}( \pm 4)$, and only 3 patients (5\% of the global cohort) remained hypokyphotic at latest follow-up. Most importantly, the reduction maneuver did not significantly affect the 3D location of the UIV ( $\mathrm{p}=0.171$ ), despite a slight but not clinically significant increase of the T1-UIV distance $(3 \mathrm{~mm}, \mathrm{p}<0.001)$ being reported (Table 2).

\section{Axial correction}

The apical rotation was significantly reduced after surgery $(\mathrm{p}<0.001)$, and the AVR correction rate averaged $42.2 \%$ (gain ranged from $0^{\circ}$ to $25^{\circ}$ ), without any direct derotation maneuver (Figure 2). No correlation was found between the axial and sagittal correction of the apex $\left(\mathrm{R}^{2}=0.005\right)$. The LIV axial rotation significantly decreased from $6^{\circ}( \pm 4)$ to $4^{\circ}( \pm 3)(\mathrm{p}=0.015)$, and remained stable over time. A residual axial rotation of the LIV $>10^{\circ}$ was reported in 2 cases $(3.3 \%)$, and these 2 patients also had a residual axial rotation of the $\mathrm{LIV}+1>10^{\circ}$. One of them developed a radiological adding-on at 6 month postoperative, without revision surgery to date. The LIV+1 axial rotation also significantly decreased immediately after the main curve correction $\left(1^{\circ}\right.$ on average), but increased in the same direction in 14 cases $(23 \%)$ (Figure 2), and in the opposite direction in 4 cases (6\%). However, spontaneous improvement was observed during follow-up and the LIV +1 axial rotation was only $3^{\circ}$ at latest examination (Table 1).

\section{Complications}

No instrumentation failure, no pseudarthrosis and no significant loss of correction was reported in the cohort during the follow-up period. Two (3.3\%) early surgical site infections (within 4 weeks) were reported, all due to Propionibacterium acnes. Implant retention strategy 
was applied, and outcomes were favourable after 1 surgical debridement followed by 12 weeks of antibiotherapy ( 2 weeks IV and 10 weeks oral). According to Yagi et al. criteria, 1 radiological proximal junctional kyphosis (PJK) occurred (6.6\%) [37]. The patient was asymptomatic and no revision was performed. One patient developed an aorto-mesenteric clamp syndrome at 6 days postoperative, which spontaneously resolved after 10 days of nasogastric decompression and intravenous hyperalimentation. This patient had a $72^{\circ}$ Lenke 1A- curve with severe hypokyphosis $\left(1^{\circ}\right.$ of T4T12 sagittal Cobb). Her curve was corrected to $25^{\circ}$ postoperatively (65\% correction) and the T4T12 thoracic kyphosis gained $12^{\circ}$ after surgery.

\section{DISCUSSION}

Results of this series confirm the ability of sublaminar bands to correct the deformity in $3 \mathrm{D}$, without altering sagittal balance. The main advantage of the current study is that only 3D measurements were used for analysis. Indeed, Newton et al. have demonstrated that most of the 2D sagittal Cobb measurements were biased, and clearly underestimated the real thoracic spine flattening [38].

\section{Limitations of all-screw constructs}

The development and rapid expansion of pedicle screws in AIS has increased construct stability, improving early postoperative care and fusion rates, but has also allowed the application of greater reduction forces with direct vertebral rotation techniques $[5,6]$. However, the spine community should acknowledge that the increased complexity of AIS surgical correction procedures has been associated not only with better initial outcomes, but also with more postoperative complications [39]. For example, PJK was rarely described after 
CD instrumentation using hooks and hybrid constructs, whereas it is now considered a topic of much interest and still not fully understood [40]. One potential explanation is that while lumbar lordosis is usually preserved after the correction, thoracic pedicle screws associated with derotation have a tendency to flatten the thoracic spine, resulting in a posterior shift of the UIV [11]. Since most AIS patients are sagitally balanced preoperatively (in opposition to adult spine deformity with anterior imbalance), the early consequence is a junctional kyphosis above the instrumented levels in order to replace the center of gravity where it stood before surgery. This phenomenon can be appreciated by the UIV-T1 3D measure. Hence, maintaining or restoring thoracic sagittal alignment without significantly modifying the preoperative location of the UIV should be considered a major goal in AIS surgery. Nonetheless, axial plane correction should not be neglected, since it is associated to the rib hump reduction, still a key factor in patient satisfaction with post-surgical outcome.

\section{Modern hybrid constructs}

The concept of posteromedial translation reduction technique has been introduced by Asher et al. (Isola system) in the early 1990's with satisfactory clinical and radiological outcomes at 10-year follow-up [24]. The system integrated hooks, wires and screws, and the largest corrections in the 11-year series of 185 patients reached $63 \%$ in the frontal plane and $39 \%$ for angle trunk inclination (related to axial correction of the apical vertebra). The principal problems identified at the time were the need for stronger transverse connectors, stable endinstrumented vertebrae foundations, and convex thoracic anchorage [24].

All these weaknesses have been efficiently addressed by modern hybrid constructs combining pedicle screws, sublaminar bands and proximal stable claws. As a matter of fact, Jazz claws are made of angled supralaminar hooks connected with a dedicated sublaminar bands, allowing connection with 2 rods (the main thoracic one, laterally, and the shorter one 
connecting UIV and UIV-1, medially) (Figure 1). Once the UIV-1 band has been tensioned, contraction is applied on the supralaminar hook placed on the UIV and both set screws are locked. The bivertebral claw therefore acts like a stable implant, with strong resistance to pull-out forces during correction. Sublaminar bands also make convex thoracic anchorage easier, because the connection between the rod and the polyester band can be placed anywhere around the instrumented vertebra (above, below, medial or lateral). Its location is not dictated and limited by the anatomy, in opposition to convex screw or pedicle hook. Finally, optimizing transverse connections is also part of the frame technique concept.

\section{Advantages of the «frame » technique}

The frame reduction technique relies on 2 stiff rods (ideally $\mathrm{CoCr}$ ) precontoured in a similar manner, according to a personalized preoperative planning, and the connection of these 2 rods with a stiff and fixed transverse connector placed at the apex before tensioning the bands. The frame therefore represents a rigid construct, resistant to the posteromedial loads applied during correction, and therefore limiting rod deformation (concave flattening). Results of the current study found a mean $64 \%$ frontal correction rate, equivalent to the best results reported by Asher et al., and reached $84 \%$ in some severe $72^{\circ}$ curves [24]. However, the main objective was not to obtain the greatest frontal correction rate, but to respect spinal harmony, restoring frontal balance (T1-CHVA distance), leaving residual LIV tilt and rotation $<10^{\circ}$, and all without altering the preoperative UIV location in order to avoid PJK.

This series also confirm that hybrid constructs with the frame technique do not have the same tendency as pedicle screws to flatten the thoracic spine, and can efficiently maintain sagittal alignment, or even restore it in hypokyphotic patients (mean gain $8.5^{\circ}$ in this subgroup) (Figure 6). 
The last advantage of the frame is that after the initial posterior and medial translation of the spine obtained during the first stage of correction, the convex rod came in contact with the convex lamina, thus shifting the center of rotation of the vertebra to the contact point. Hence, the axial correction was enhanced at the end of correction maneuvers, and the unexpected increased AVR reported by Pizones et al. with sublaminar wires was avoided (Figure 5) [29]. This indirect counterclockwise rotation corresponds to a detorsion of the spine and is directly correlated to rib hump reduction. AVR correction reached $42.2 \%$ in the current series, not so far from the recent results $(55 \%)$ reported by Kato el al. using the same measurement technique (EOS 3D reconstructions) in a cohort of AIS treated with all-screw constructs using DVR [41]. Better axial corrections have already been reported with all-screw constructs when CT scan was used for assessment, but the clinical relevance of the gain of few more degrees (between 2 and $4^{\circ}$ ) at the apex needs to be further studied for both surgical techniques.

\section{Limitations}

This series is retrospective but all data were collected prospectively. AVR correction was only assessed on 3D reconstructions, and rib hump clinical measurement should be added in future studies to compare radiological outcomes and patient's satisfaction. More follow-up remains necessary to evaluate the long-term stability of these hybrid constructs, and evaluate more accurately the pseudarthrosis rate. Last, this study was only radiological and the financial cost of such constructs should be considered, with sublaminar band prices ranging on average from 600 dollars in Europe to 1450 dollars in North America.

While many surgeons currently advocate the use of thoracic pedicle screws for optimal care in AIS, sometimes associated with multiple Ponte osteotomies, sublaminar bands should be considered, especially in hypokyphotic patients, in order to reduce complication rates and in 
particular the risk of intraoperative concave screw failure due to pull-out forces $[42,43]$. The "frame" technique is an innovative way of using polyester bands, optimizing axial correction while respecting sagittal alignment. 


\section{FIGURES LEGENDS}

Figure 1: Preoperative (a) and postoperative (b) frontal radiographs of a $51^{\circ}$ Lenke $1 \mathrm{~A}$ curve, who underwent a T3L3 fusion using Jazz claw for the upper fixation.

Figure 2: Preoperative (a) and postoperative (b) AP radiographs of a $48^{\circ}$ Lenke $1 \mathrm{~A}$ curve, who underwent a T3L2 fusion using Instinct autostable claw for the upper fixation. Frontal correction rate reached $64.5 \%$ with only 3 concave sublaminar bands. The frame allowed to obtain $43 \%$ of axial correction at the apex, while the sagittal alignment was maintained.

Figure 3: Insertion of two 30mm length fixed transverse connectors in order to obtain a rigid « frame ».

Figure 4: Bilateral connection of the frame with the upper anchors after initial lumbar correction.

Figure 5: Top view of the apical vertebra, showing the contact between the convex rod and the rotated right lamina during correction, resulting in a posterior shift of the vertebral center of rotation.

Figure 6: Preoperative (A) and postoperative (B) frontal and lateral radiographs of an 18year-old girl who presented a $73^{\circ}$ Lenke $1 \mathrm{~A}$ with right frontal imbalance and hypokyphosis $\left(\mathrm{T} 4 \mathrm{~T} 1213^{\circ}\right)$. The main thoracic curve was instrumented with 5 concave sublamnair bands and T4T12 sagittal Cobb was restored to $31^{\circ}$ postoperatively. 


\section{REFERENCES}

[1]. Winter RB, Lonstein JE, Denis F. How much correction is enough? Spine 2007; 32(24):2641-3.

[2]. Rushton PRP, Grevitt MP. Comparison of untreated adolescent idiopathic scoliosis with normal controls: a review and statistical analysis of the literature. Spine 2013 Apr; 38(9):778-85.

[3]. Ward WT, Friel NA, Kenkre TS, Brooks MM, Londino JA, Roach JW. SRS-22r Scores in Non-Operated Adolescent Idiopathic Scoliosis Patients with Curves Greater than Forty Degrees. Spine 2017; 42(16): 1233-1240

[4]. Rushton PRP, Grevitt MP. What is the effect of surgery on the quality of life of the adolescent with adolescent idiopathic scoliosis? A review and statistical analysis of the literature. Spine 2013; 38(9):786-94.

[5]. Pankowski R, Roclawski M, Ceynowa M, Mikulicz M, Mazurek T, Kloc W. Direct Vertebral Rotation Versus Single Concave Rod Rotation: Low-dose Intraoperative Computed Tomography Evaluation of Spine Derotation in Adolescent Idiopathic Scoliosis Surgery. Spine 2016; 41(10):864-71.

[6]. Suk S-I, Kim J-H, Kim S-S, Lim D-J. Pedicle screw instrumentation in adolescent idiopathic scoliosis (AIS). Eur Spine J 2012; 21(1):13-22.

[7]. Lowenstein JE, Matsumoto H, Vitale MG, Weidenbaum M, Gomez JA, Lee FY-I, et al. Coronal and sagittal plane correction in adolescent idiopathic scoliosis: a comparison between all pedicle screw versus hybrid thoracic hook lumbar screw constructs. Spine 2007; 32(4):448-52.

[8]. Hwang SW, Samdani AF, Tantorski M, Cahill P, Nydick J, Fine A, et al. Cervical sagittal plane decompensation after surgery for adolescent idiopathic scoliosis: an effect imparted by postoperative thoracic hypokyphosis. J Neurosurg Spine 2011; 15(5):491-6. 
[9]. Martin CT, Pugely AJ, Gao Y, Mendoza-Lattes SA, Ilgenfritz RM, Callaghan JJ, et al. Increasing hospital charges for adolescent idiopathic scoliosis in the United States. Spine 2014; 39(20):1676-82.

[10]. Newton PO, Yaszay B, Upasani VV, Pawelek JB, Bastrom TP, Lenke LG, et al. Preservation of thoracic kyphosis is critical to maintain lumbar lordosis in the surgical treatment of adolescent idiopathic scoliosis. Spine 2010; 35(14):1365-70.

[11]. Watanabe K, Nakamura T, Iwanami A, Hosogane N, Tsuji T, Ishii K, et al. Vertebral derotation in adolescent idiopathic scoliosis causes hypokyphosis of the thoracic spine. BMC Musculoskelet Disord. 2012; 13:99.

[12]. Larson AN, Aubin C-E, Polly DW, Ledonio CGT, Lonner BS, Shah SA, et al. Are More Screws Better? A Systematic Review of Anchor Density and Curve Correction in Adolescent Idiopathic Scoliosis. Spine Deform. 2013; 1(4):237-47.

[13]. Yang S, Jones-Quaidoo SM, Eager M, Griffin JW, Reddi V, Novicoff W, et al. Right adolescent idiopathic thoracic curve (Lenke $1 \mathrm{~A}$ and $\mathrm{B}$ ): does cost of instrumentation and implant density improve radiographic and cosmetic parameters? Eur Spine J 2011; 20(7):1039-47.

[14]. Bharucha NJ, Lonner BS, Auerbach JD, Kean KE, Trobisch PD. Low-density versus high-density thoracic pedicle screw constructs in adolescent idiopathic scoliosis: do more screws lead to a better outcome? Spine J 2013; 13(4):375-81.

[15]. Hwang CJ, Lee C-K, Chang B-S, Kim M-S, Yeom JS, Choi J-M. Minimum 5-year follow-up results of skipped pedicle screw fixation for flexible idiopathic scoliosis. J Neurosurg Spine 2011; 15(2):146-50.

[16]. Lamerain M, Bachy M, Delpont M, Kabbaj R, Mary P, Vialle R. CoCr rods provide better frontal correction of adolescent idiopathic scoliosis treated by all-pedicle screw fixation. Eur Spine J 2014; 23(6):1190-6. 
[17]. Sudo H, Abe Y, Kokabu T, Ito M, Abumi K, Ito YM, et al. Correlation analysis between change in thoracic kyphosis and multilevel facetectomy and screw density in main thoracic adolescent idiopathic scoliosis surgery. Spine J 2016; 16(9):1049-54.

[18]. Ferrero E, Pesenti S, Blondel B, Jouve JL, Mazda K, Ilharreborde B. Role of thoracoscopy for the sagittal correction of hypokyphotic adolescent idiopathic scoliosis patients. Eur Spine J 2014; 23(12):2635-42.

[19]. Mazda K, Ilharreborde B, Even J, Lefevre Y, Fitoussi F, Penneçot G-F. Efficacy and safety of posteromedial translation for correction of thoracic curves in adolescent idiopathic scoliosis using a new connection to the spine: the Universal Clamp. Eur Spine J 2009; 18(2):158-69.

[20]. Ilharreborde B, Sebag G, Skalli W, Mazda K. Adolescent idiopathic scoliosis treated with posteromedial translation: radiologic evaluation with a 3D low-dose system. Eur Spine J 2013; 22(11):2382-91.

[21]. Luque ER. Segmental spinal instrumentation for correction of scoliosis. Clin Orthop Relat Res 1982; (163):192-8.

[22]. McMaster MJ. Luque rod instrumentation in the treatment of adolescent idiopathic scoliosis. A comparative study with Harrington instrumentation. J Bone Joint Surg Br 1991; 73(6):982-9.

[23]. Dove J. Luque segmental spinal instrumentation: the use of the Hartshill rectangle. Orthopedics. 1987; 10(6):955-61.

[24]. Asher M, Lai SM, Burton D, Manna B, Cooper A. Safety and efficacy of Isola instrumentation and arthrodesis for adolescent idiopathic scoliosis: two- to 12-year follow-up. Spine 2004; 29(18):2013-23.

[25]. Polirsztok E, Gavaret M, Gsell T, Suprano I, Choufani E, Bollini G, et al. Sublaminar bands: are they safe? Eur Spine J 2015; 24(7):1441-9. 
[26]. Albert MC, LaFleur BC. Hybrid fixation with sublaminar polyester bands in the treatment of neuromuscular scoliosis: a comparative analysis. J Pediatr Orthop 2015; $35(2): 172-7$.

[27]. Sales de Gauzy J, Jouve J-L, Ilharreborde B, Blondel B, Accadbled F, Mazda K. Use of the Universal Clamp in adolescent idiopathic scoliosis. Eur Spine J 2014; 23 Suppl 4: S446-451.

[28]. Gazzeri R, Faiola A, Galarza M, Tamorri M. Universal Clamp system in thoracolumbar spinal fixation: technical note. Acta Neurochir (Wien) 2009; 151(12):1673-80. [29]. Pizones J, Sánchez-Mariscal F, Zúñiga L, Izquierdo E. The effect of sublaminar wires on the rib hump deformity during scoliosis correction manoeuvres. Eur J Orthop Surg Traumatol 2016; 26(7):771-7.

[30]. Angelliaume A, Ferrero E, Mazda K, Le Hanneur M, Accabled F, de Gauzy JS, et al. Titanium vs cobalt chromium: what is the best rod material to enhance adolescent idiopathic scoliosis correction with sublaminar bands? Eur Spine J 2017; 26(6):1732-8.

[31]. Ilharreborde B, Pesenti S, Ferrero E, Accadbled F, Jouve J-L, De Gauzy JS, et al. Correction of hypokyphosis in thoracic adolescent idiopathic scoliosis using sublaminar bands: a 3D multicenter study. Eur Spine J 2017. Epub upon ahead of print [32]. Humbert L, Steffen J-S, Vialle R, Dubousset J, Vital J-M, Skalli W. 3D analysis of congenital scoliosis due to hemivertebra using biplanar radiography. Eur Spine J 2013; 22(2):379-86.

[33]. Dubousset J, Charpak G, Dorion I, Skalli W, Lavaste F, Deguise J, et al. A new 2D and 3D imaging approach to musculoskeletal physiology and pathology with low-dose radiation and the standing position: the EOS system. Bull Académie Natl Médecine 2005; 189(2):287-297-300.

[34]. Ilharreborde B, Steffen JS, Nectoux E, Vital JM, Mazda K, Skalli W, et al. Angle 
measurement reproducibility using EOS three-dimensional reconstructions in adolescent idiopathic scoliosis treated by posterior instrumentation. Spine 2011; 36(20): E1306-1313. [35]. Vidal C, Ilharreborde B, Azoulay R, Sebag G, Mazda K. Reliability of cervical lordosis and global sagittal spinal balance measurements in adolescent idiopathic scoliosis. Eur Spine J 2013; 22(6):1362-7.

[36]. Ilharreborde B, Even J, Lefevre Y, Fitoussi F, Presedo A, Penneçot G-F, et al. Hybrid constructs for tridimensional correction of the thoracic spine in adolescent idiopathic scoliosis: a comparative analysis of universal clamps versus hooks. Spine 2010; 35(3):30614.

[37]. Yagi M, Rahm M, Gaines R, Maziad A, Ross T, Kim HJ, et al. Characterization and surgical outcomes of proximal junctional failure in surgically treated patients with adult spinal deformity. Spine 2014; 39(10): E607-614.

[38]. Newton PO, Fujimori T, Doan J, Reighard FG, Bastrom TP, Misaghi A. Defining the "Three-Dimensional Sagittal Plane" in Thoracic Adolescent Idiopathic Scoliosis. J Bone Joint Surg Am 2015; 97(20):1694-701.

[39]. Helenius I, Remes V, Yrjönen T, Ylikoski M, Schlenzka D, Helenius M, et al. Harrington and Cotrel-Dubousset instrumentation in adolescent idiopathic scoliosis. Longterm functional and radiographic outcomes. J Bone Joint Surg Am 2003; 85-A(12):2303-9. [40]. Lonner BS, Ren Y, Newton PO, Shah SA, Samdani AF, Shufflebarger HL, et al. Risk Factors of Proximal Junctional Kyphosis in Adolescent Idiopathic Scoliosis-The Pelvis and Other Considerations. Spine Deform 2017; 5(3):181-8.

[41]. Kato S, Debaud C, Zeller RD. Three-dimensional EOS Analysis of Apical Vertebral Rotation in Adolescent Idiopathic Scoliosis. J Pediatr Orthop 2017 ;37(8):e543-7.

[42]. de Kleuver M, Lewis SJ, Germscheid NM, Kamper SJ, Alanay A, Berven SH, et al. Optimal surgical care for adolescent idiopathic scoliosis: an international consensus. Eur 
Spine J $2014 ; 23(12): 2603-18$.

[43]. Quan GMY, Gibson MJ. Correction of main thoracic adolescent idiopathic scoliosis using pedicle screw instrumentation: does higher implant density improve correction? Spine $2010 ; 35(5): 562-7$. 



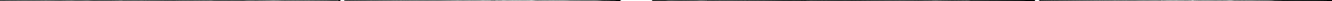




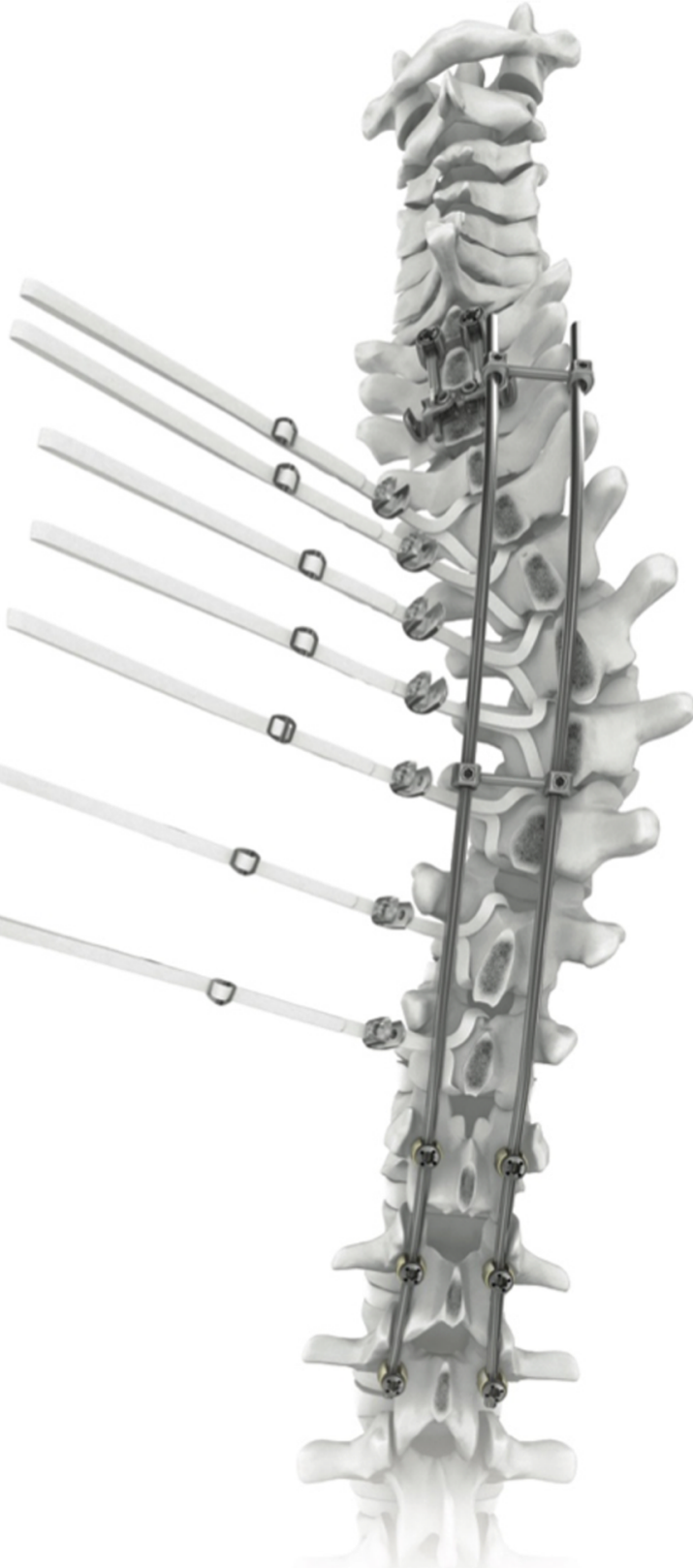




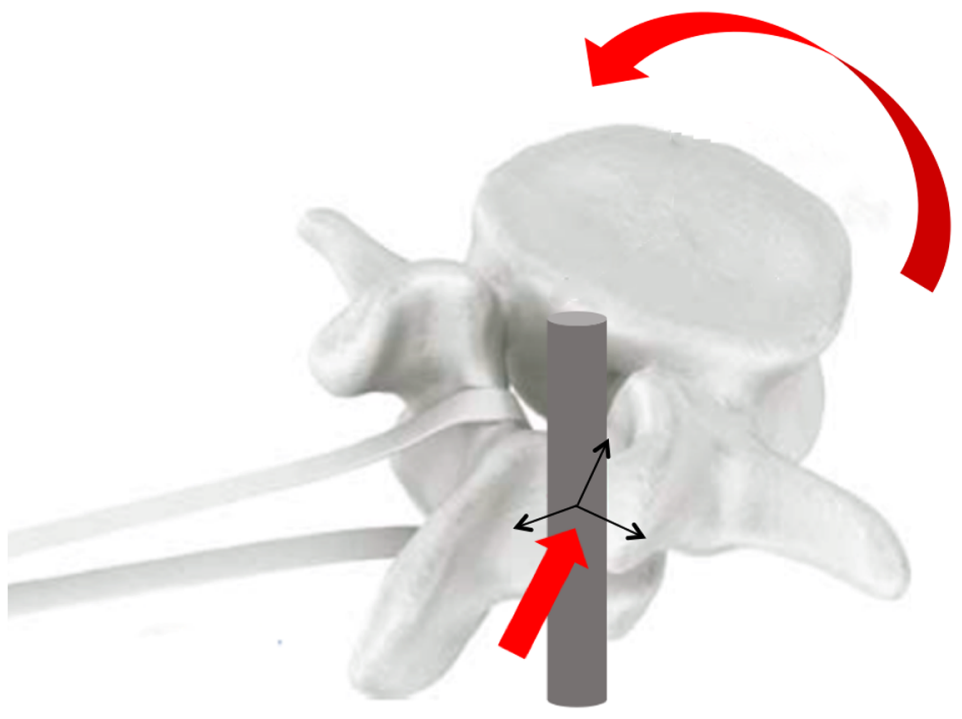


19xyrer

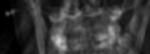

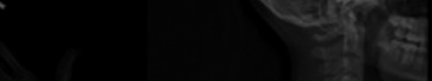

(4)

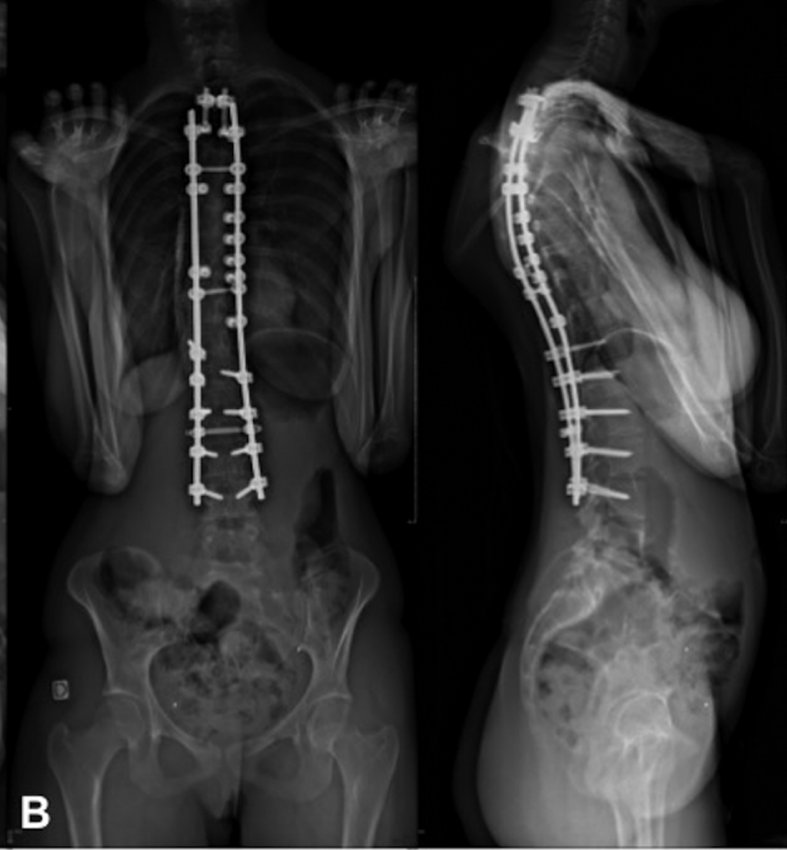

A

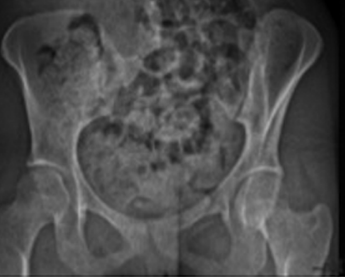

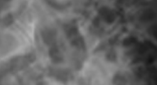

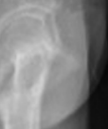


Table 1: Preoperative and postoperative $3 \mathrm{D}$ measurements (mean \pm standard deviation)

\begin{tabular}{|c|c|c|c|}
\hline & Preoperative & Postoperative & Latest follow-up \\
\hline Main Cobb angle $\left(^{\circ}\right)$ & $56 \pm 11$ & $\begin{array}{c}20 \pm 7 \\
p<0.001\end{array}$ & $\begin{array}{c}22 \pm 6 \\
n s\end{array}$ \\
\hline $\operatorname{AVR}\left({ }^{\circ}\right)$ & $19 \pm 6$ & $\begin{array}{c}11 \pm 5 \\
p<0.001\end{array}$ & $\begin{array}{c}12 \pm 5 \\
n s\end{array}$ \\
\hline T1T12 sagittal Cobb $\left(^{\circ}\right)$ & $28 \pm 12$ & $\begin{array}{l}35 \pm 11 \\
p<0.001\end{array}$ & $\begin{array}{c}37 \pm 8 \\
n s\end{array}$ \\
\hline T4T12 sagittal $\operatorname{Cobb}\left(^{\circ}\right)$ & $20 \pm 11$ & $\begin{array}{c}21 \pm 8 \\
p=0.719\end{array}$ & $\begin{array}{c}21 \pm 7 \\
n s\end{array}$ \\
\hline L1S1 sagittal Cobb $\left(^{\circ}\right)$ & $57 \pm 9$ & $\begin{array}{l}54 \pm 10 \\
p=0.002\end{array}$ & $\begin{array}{c}55 \pm 8 \\
n s\end{array}$ \\
\hline T1 frontal tilt $\left(^{\circ}\right)$ & $5 \pm 4$ & $\begin{array}{c}6 \pm 5 \\
p<0.001\end{array}$ & $\begin{array}{c}5 \pm 5 \\
n s\end{array}$ \\
\hline LIV axial rotation $\left(^{\circ}\right)$ & $6 \pm 4$ & $\begin{array}{c}4 \pm 3 \\
p<0.001\end{array}$ & $\begin{array}{c}4 \pm 4 \\
n s\end{array}$ \\
\hline LIV +1 axial rotation $\left(^{\circ}\right)$ & $5 \pm 3$ & $\begin{array}{c}4 \pm 3 \\
p<0.001\end{array}$ & $\begin{array}{c}3 \pm 3 \\
p<0.001\end{array}$ \\
\hline Pelvic incidence $\left({ }^{\circ}\right)$ & $52 \pm 11$ & $\begin{array}{l}52 \pm 11 \\
p=0.447\end{array}$ & $\begin{array}{c}52 \pm 10 \\
n s\end{array}$ \\
\hline Sacral slope $\left(^{\circ}\right)$ & $44 \pm 7$ & $\begin{array}{c}43 \pm 9 \\
p=0.281\end{array}$ & $\begin{array}{c}44 \pm 9 \\
n s\end{array}$ \\
\hline Pelvic tilt $\left(^{\circ}\right)$ & $9 \pm 8$ & $\begin{array}{c}9 \pm 8 \\
p=0.426\end{array}$ & $\begin{array}{c}10 \pm 9 \\
n s\end{array}$ \\
\hline
\end{tabular}

AVR: axial rotation of the apical vertebra ns : non significant $p$-value 
Table 2 : Preoperative and postoperative 3D parameters of global balance, measured in regards to the Central Hip Vertical Axis (CHVA)

\begin{tabular}{|c|c|c|c|}
\hline & Preoperative & Postoperative & $\mathrm{p}$ \\
\hline Frontal T1 distance (cm) & $1.3 \pm 1$ & $1.4 \pm 1$ & 0.846 \\
\hline Sagittal T1 distance (cm) & $3.4 \pm 2$ & $3.4 \pm 2$ & 0.737 \\
\hline Frontal UIV distance (cm) & $1.2 \pm 1$ & $1.5 \pm 1$ & 0.181 \\
\hline Sagittal UIV distance (cm) & $3.9 \pm 2$ & $4.2 \pm 2$ & 0.171 \\
\hline Frontal LIV distance (cm) & $1.2 \pm 1$ & $1.0 \pm 1$ & 0.075 \\
\hline Sagittal LIV distance (cm) & $1.3 \pm 1$ & $1.5 \pm 1$ & 0.387 \\
\hline Frontal T1-UIV distance (cm) & $0.4 \pm 0.3$ & $0.4 \pm 0.3$ & 0.999 \\
\hline Sagittal T1-UIV distance (cm) & $0.6 \pm 0.5$ & $0.9 \pm 0.5$ & $<\mathbf{0 . 0 0 1}$ \\
\hline
\end{tabular}

UIV : upper instrumented vertebra

LIV : lower instrumented vertebra 